\title{
Crafting social innovators: Designing collaborative, participative, networked solutions in urban contexts
}

\author{
Marzia Mortati and Beatrice Villari
}

\begin{abstract}
This paper addresses the potential of design as a driver for social innovation in urban contexts in relation to an educational approach engaged with an idea of crafting social innovators. The focus is a masters studio where the idea of crafting social innovators as an approach to learning is explored in terms of learning through making, through doing and, then, how this approach extended into the actual design propositions of the studio. In this paper, six projects are presented that explore the topics of creativity, neighbours networks, and local craft in urban contexts. These detail both the idea of crafting social innovators and the results of the work as makers of social innovation. In particular, the solutions also extended further into an idea of what we have called 'a temporarycommunity of makers'; i.e., groups of people who share objectives, tools, and resources to collaborate for a limited time and describe a way in which design can enable urban regeneration through participating in a learning process that is based in practice.
\end{abstract}

A new role for design emerges that is concerned with: looking for cocreated collective meaning and action (networking); focusing on the participative process that builds a solution (participating); and centring the design activity on the active collaboration of stakeholders (collaborating).

\section{Introduction}

Design is currently considered a cross-functional and multidisciplinary innovation activity, capable of making sense of social challenges while devising strategic and holistic solutions to support competitiveness. It is considered a fundamental ingredient in business innovation through its ability to shape ideas and translate them into practical and appealing propositions for users, while improving national performance. Moreover design practices include issues of social, and non-technological innovation (EU 2009), devising relationships, citizen participation, companies/institutions cooperation, and organisational transformation.

In this nuanced relationship between design and innovation, this paper explores in particular the meaning of educating social innovators from the perspective of design. This is paralleled with the apprenticeship model typical in craft, and applied in a masters studio, to understand the implications of the idea of 
crafting social innovators. Moreover, this provokes reflections on the evolution of the methods for educating future designers, and on the new professionals emerging from this.

We argue that social innovation applied to urban contexts is not only one of the most interesting contributions of design to innovation processes, but also a promising field to experiment on the idea of crafting people who become capable of enhancing places through a learning process based in practice. Crafting is chosen over designing to signal a specific approach to education, an approach centred on learning by doing, through making. This identifies a peculiar attitude to innovation, a way of thinking and solving problems, a way of expressing ideas that is critical to humanity, and a specific set of characteristics of the solution produced.

We start by reconnecting the meaning of social innovation to craft practices and how these are influencing urban contexts. Here, craft is a specific way to answer to social innovation issues, and to create product-service systems. Moreover, cities are a great testbed for research as they are defined by a mix of socio-economic challenges and the presence of a mix of users with contrasting needs. We filter this focus by applying a framework that links the method used to guide students, and the results obtained in the class through the assets of collaboration, participation and networking.

To develop the discourse we use the field experience of a six-month masters studio in product/service system design at the Design School of Politecnico di Milano, where we have led students to look at social innovation in urban contexts with a craft approach - through crafting.

Finally, we reflect on the method used to craft social innovators, on the people crafted (the makers of social innovation), on the results of the people's work (the product/service systems designed). A series of characteristics/capacities of makers of social innovation emerge, as well as the idea of a temporary community of makers as the collective subject that realises and promotes solutions for social innovation.

The paper concludes by putting forward reflections for the future exploration of the topic as research area to define the new role of design in implementing transformation and growth.

\section{Social innovation and craft practices in the urban context}

Social innovation focuses on improving social outcomes and creating value for people, places and organisations. In particular, it relates to new ideas that successfully implemented - provoke a positive transformation for society and its infrastructure (people, relationships, collaborations), thus improving society's capacity to act (BEPA 2011). Social innovation relates to design at multiple levels, as it concerns solutions that integrate new products, services and 
systems that respond to social needs. Citizens are engaged directly to promote their empowerment and provoke action and change, as they have an active role in the design, production, and distribution of goods (Cottam \& Leadbeter 2004; Botsman \& Rogers 2010). This is also happening in production/distribution systems, and in governmental processes, where public administration is increasingly interested in experimenting with user-centric processes and tools, and in considering citizens not only as targets but as active agents of change (Bovaird 2007; Lukensmeyer 2007).

In the design field, the attention to user involvement is highlighted by participative and collaborative approaches (e.g., user-centred design, participatory design, co-design, emancipatory design, community-centred design, human-centred design) increasingly looking at new ways to support collective creativity and collaboration between designers and everyday people (Sanders 2006). These argue for the importance of involving users and citizens during the whole design process with different roles (e.g., to give feedback or to become codecision makers) and with slight differences in the stages and techniques for engagement (Holmlid 2009; Bradwell \& Marr 2008; Sanders \& Stappers 2008). In addition, more systemic approaches have recently been promoted, such as Transformation Design (Burns et al. 2006; Sangiorgi 2011), the focus of which considers both the engagement of users, and the impact of the intervention, to point out that a good solution should leave behind tools to keep adapting to the situation. The user involvement is a process to democratise design activities while listening to the needs of a wider audience; at the same time, it is also a way to engage people in a learning process. People learn and share their skills and their knowledge with other people contributing in defining new tools and languages. These activities are related to practices that are often strictly related to a specific context and to specific skills. This connects to the 'craft' activities and the 'crafting' process, in which learning by doing is fundamental.

These examples highlight design as especially suited to intervene in social innovation, looking for the most appropriate tools to devise solutions that are relevant both to meeting social needs and to creating new relationships and collaboration.

Social innovation is relevant when applied to urban contexts, where both economic and social needs are present, and where a multiplicity of actors participates in generating growth. Cities are key places where social, cultural and entrepreneurial change happens. They are laboratories for experimentation, where innovation and transformational activities are devised from citizens, organisations, and public administrations, by networks of interacting projects, information, goods, people, and hubs of knowledge exchange (Landry 2000; 2006). Cities are the core of current economic systems where flows of ideas, people, and resources can be variably connected and intertwined, and offer the opportunity to experiment on governance systems as well as on new ways to acquire skills and improve techniques (Bonomi \& Bruzzese 2004). 
Some cities have recently undergone the transformations needed to answer to the changing nature of jobs and human life, as well as to the new challenges society and economy are facing. For example, as jobs have increasingly shifted from hardware to software - that is shifted from a close concentration on manual skills to an attention to knowledge and immaterial goods - cities have also evolved towards modifying their infrastructures. In the twentieth century, manufacturing moved increasingly out of urban systems to privilege the immaterial nature of virtual networks for the exchange of knowledge and information. As a result, cities have become intertwined and intricate systems designed especially for those parts of the population with high educational levels and high income, thus leaving little space for manual labour and lower classes. At a certain point in the evolution of globalisation, we registered an increase in the disparity between higher and lower classes: rich people were becoming richer, and poor ones were being further confirmed in that condition.

With the environmental and financial crisis, we are registering a counter trend: social innovation and collaboration are becoming buzzwords to awaken the spirit of citizens. These are stepping forward to encourage communities to renew the places in which they live, envisage sustainable and socially viable innovations, and suggest new ways to make things capable of putting people and local resources at the core of the reconstruction needed to devise alternatives to the current situation. Initiatives like Breakthrough Cities (http://creativecities. britishcouncil.org), Collaborative Cities (http://collaborative-cities.com), San Francisco Made (SFMade - http://www.sfmade.org) signal the importance that citizens place not only on participating in the life and construction of their city, but also to the possibility of making things with their hands to contribute to creating a thriving local community. For example, SFMade aims at supporting the renaissance of a vibrant manufacturing sector in San Francisco through sustaining companies that produce locally. The overarching objectives of such statements include encouraging entrepreneurship and innovation, creating new job opportunities for local workforces, contributing to establishing a sustainable local economic system, offering diverse educational opportunities, and raising public awareness on the importance of local craft practice and of the role of craftspeople in the local community. Collaborative Cities is a series of documentary films on cities in North America and Europe (among them are New York, Toronto, Helsinki and Paris) depicting how people are reshaping agriculture, transportation, housing, finance through valuing craft and locality. These solutions are examples of successful social innovations, and of the revived importance of craft in cities. As Richard Sennet argues (2008), craftsmanship is the skill of making things well, but mostly it is the basic human need of doing a job well. It goes beyond skilled manual labor, because the craftsman focuses on the special connection between hand and head. This is a dialogue between thinking and practicing that becomes concrete in learning by doing that is typical of the workshop situation in which apprentices learn from masters. The same mechanism is being adopted and reinvented in the cities of the twenty- 
first century to give life to new creative communities (Florida 2002; Thackara 2005) based on the strength of relationships, on the importance of manual work, on the value of local resources, small numbers and excellence.

These values connect social innovation and craft practices, and are a gateway to reshaping urban contexts for the future. When talking of education, this statement has a double perspective: on the one side it means educating people to become capable of working with such values, on the other it means instilling the same values in the final solutions. For designers in particular, it means reeducating the future generation to think through materials and skills, to learn to use a tool and to then modify it or invent a new one. Learning is the process of understanding and answering challenges, building on existing skills, and discovering new ones. This is the starting point for our idea of crafting social innovators - by design as a means to going beyond the functional accent of products, while seeking to shape relationships and collaborations.

\section{Research path and framework: Participation, collaboration and networking}

Purposely applied to cities, social innovation refers to the capacity of kickstarting collective and collaborative actions that reflect on new scenarios and promote solutions to enhance places and create value for people (Manzini 2011). These are centred on: citizens and communities that promote new local activities and share interests (services like heyneighbor.com, connectaid. com, and sharesomesugar.com); municipalities and governments that activate participatory processes to involve the public in urban planning and improvement of public services (initiatives such as Collaborative London); organisations and projects that leverage on territorial capacities to create new jobs (initiatives like progettokublai.net and innovetionvalley.com).

Generating these kinds of solution is a task that requires craft, in terms of the ability of learning by using the connection between hand and head. This means, for example, getting to fully know a place and its resources before engaging with its transformation, learning through experimenting in reality, recognising and valuing local excellence.

The aim of the research presented here - started in 2011 and still ongoing - is understanding how to educate people with such skills and capabilities, working through three phases:

1. exploring, based on mapping and collecting interesting cases and people

2. experimenting, through a real educational project to extend on the initial findings

3. testing, through a design research project in which students are directly involved to define new urban services. 


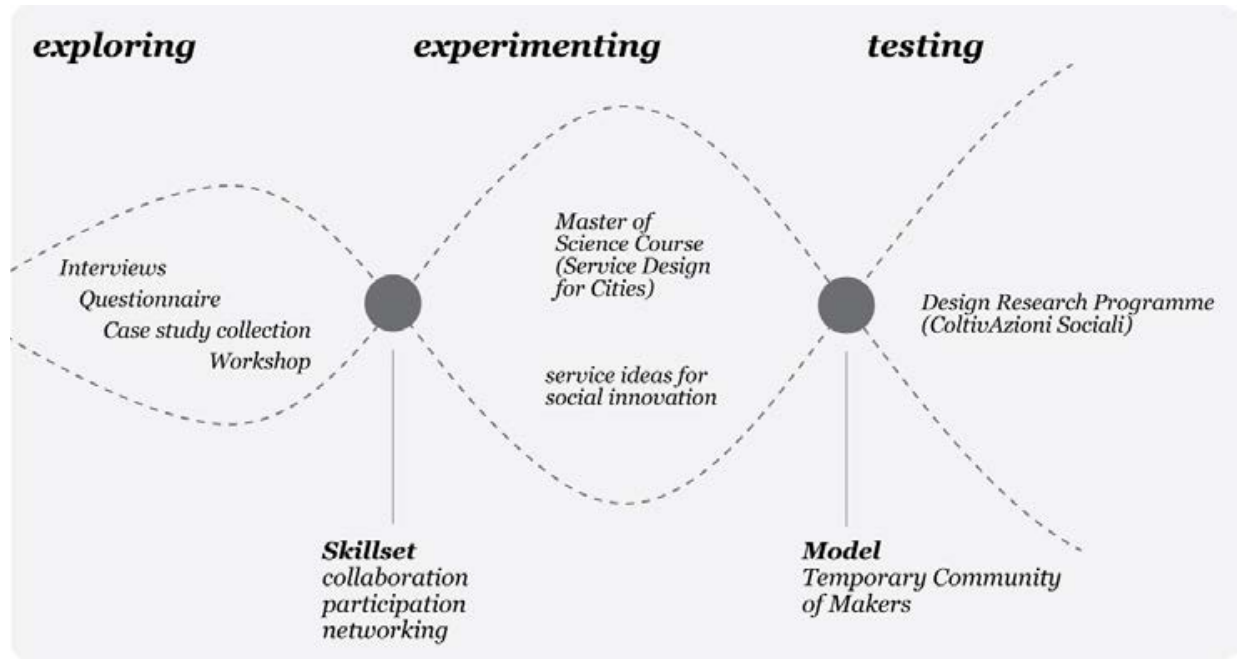

Figure 1. Process of crafting social innovators.

Diagram: Marzia Mortati and Beatrice Villari

The output of the first phase is a map of interesting cases in the Italian context, and a comparison with international best practices. A series of interviews with experts from diverse fields (service design agencies, government bodies, universities, policy advisors, and design practitioners) has also been carried out, aiming at pinning down the different viewpoints concerning practical approaches and tools, research areas and methodologies, and political concerns. This has generated an initial empirical understanding of the topic, further developed through an expert workshop held at Politecnico di Milano in March 2011. ${ }^{1}$ The workshop investigated the connection between design, social innovation, and craft practices in three main areas: individuals - connecting people for social change, companies - connecting small and medium enterprises (SMEs) and design for innovation, places - connecting and collaborating for sustainability. An online knowledge repository was created from the work that was developed and discussed. ${ }^{2}$ This shares the elements of the workshop as well as mapping and promoting promising cases at national and international level.

The explorative action has been useful in defining the appropriate skillset for crafting social innovators, referring mainly to the three assets of collaboration, participation, and networking. This was then transferred to the experimenting phase in a concrete action for testing the model built around the idea of crafting social innovators. This was embodied in the design studio, which explored in practice three different levels of the model:

1. The educational action/method to transfer the above capabilities to young designers.

2. The peculiarities of the solutions that emerged from students. 
3. The viability of these solutions as social innovations.

The results of the above have established the basis for the testing phase. This has just started and foresees the development of a research project aimed at crafting service solutions for local communities through crafted social innovators. ColtivAzioni Sociali ${ }^{3}$ is an action-research project based in Milan that aims to enhance social cohesion locally by activating new services at the neighbourhood scale.

In the remainder of this paper we focus on the educational experience, as the first stage of this ongoing project to reflect critically on the hypotheses of the paper - the idea of crafting social innovators.

\section{The skillset of social innovators}

As reported above, the first important output of the explorative phase has been a description of the appropriate skillset for social innovators. This set of skills refers to the three assets that emerged as the central focus in social innovation solutions:

- Collaboration: the need and ability to use creativity as the stimulus for connections between local actors, and to provoke growth through negotiating growth.

- Participation: the ability to empower local stakeholders, and support learning through opening up solutions and engaging citizens directly.

- Networking: the importance of thinking systemically through understanding and maximising relationships and connecting all material and immaterial elements in a context (people, places, infrastructures, history, tradition, knowledge, know-how).

Each of these assets was then translated into a set of connected skills:

Collaboration, translated into the skill of leveraging collective creativity to address social needs - designers have tools and methods at their disposal that are useful in stimulating shared creativity as well as fostering co-production of meaning and solutions. For example, they are good at focusing on human experiences and on the human scale of solutions. They foster conversation to co-produce meaning in the social world by asking 'what are we doing in this room right now, what are the objects, what are the human interactions?' (APDIG 2013). Designers consistently care about people, and about crafting interactions from the beginning.

Participation, translated in the skills of enabling co-created solutions and actions, and achieving the emancipation of users through owning the solution. This means triggering engagement, and developing social sharing platforms. Designers give particular attention to user involvement, and actively look for new ways to support collective creativity and collaboration with citizens (Sanders, 2006).

3 http://www.coltivazionisociali.org 
Networking, translated in the skills of rearranging organisational processes to regenerate/adapt solutions, and building effective relationships (between all elements of the system) for resilience through creating interdependence and links between ideas and meanings. Designers create systemic and holistic visions due to their tendency to consider problems more broadly. Charles Owen (2007) signals design as a profession capable of treating problems as systemic challenges calling for systemic solutions that involve a mix of hardware, software, procedures, policies, organisational concepts and whatever else is necessary to create a holistic solution.

\section{The educational framework for crafting social innovators}

The skillset described has been the basis for developing a teaching approach to craft social innovators. This is also seeking to apply two fundamental principles of crafting, adapted from Sennet (2008) and Christopher Frayling (2011) and the idea of the craftsman, Donald Schön (1983) and the characteristics he attributed to the reflective practitioner, Etienne Wenger (1998) and his theory of learning developed around the concept of communities of practice. In particular, these authors argue in diverse and complementary fields for the need to closely link practice and reflection for certain kinds of practitioners. This is central both to understanding problems and to learning, creating a direct link between sharing experiences, devising communities, and making through manual skills. We have organised this approach into two main principles:

- the learning by doing approach, signalling a focus on practice-based learning which engages young designers in developing their attitude to learning through making (objects, relationships and services). The importance of the apprenticeship model is thus revived based on sharing knowledge between expert and trainee through participating in contextualised workshops activities.

- the thinking by prototyping attitude, which means solving complex problems through testing, examining, and reflecting on prototypes. These are models of the real world that help make visible and tangible abstract ideas to refine them and experiment with their real constraints.

These principles suit the complexity of social innovation solutions in urban contexts, where problems need to be investigated and experimented directly in the field, in a continuous process of learning by doing. Iterative cycles of diverging and converging phases merged with action and reflection are needed, typical of a designerly way of solving ill-defined problems.

According to this framework, students deployed iterative cycles of qualitative research - in particular contextual analysis in the assigned urban context - to identify opportunities and to involve directly local people. Each analysis was conducted in a specific area of the city (Milan), to include and consider its ethnic groups, culture and resources, jobs and business characteristics (tourism, commerce and culture). Students were prompted to look also for existing cases 
to test ideas. They described, visualised, and detailed concepts through testing the service ideas and business hypothesis, and gathering feedback. In the final part of the process, they built a simulated prototype to define also the intangible qualities of a design solution, while detailing all levels of the service organisation: system map, technical aspects, offering, touchpoints, user experience, service storytelling and business model. The prototyping phase was a critical part of the process, because students engaged in a verification of ideas in context, and shifted from an abstract understanding to a real simulation.

The learning model that emerged is strongly linked to the skillset proposed: collaboration was represented by the use/creation of collaborative tools and processes aimed at co-designing and co-producing solutions; participation was reflected in the involvement of people in the design process, and in the embeddedness of participatory mechanisms in the final solutions; networking concerned the inclusion of enabling platforms to support and improve daily life, people connections, new enterprises and public services.

\section{The social innovation solutions crafted through the experimentation}

In the following section we describe in more detail the solutions that emerged through working with students - engaging with our idea for crafting social innovators. Focused on social innovation in cities, students were asked to look for new scenarios to enhance the territorial and social capital of Milan. Six product/service system proposals were developed in relation to three topics: city and creativity, city and neighbourhood, city and local craft. Following is a discussion of these topics and the connected solutions developed by students.

\section{City and creativity}

This topic explored issues connected to new urban manufacturing and jobs for creative practitioners. Personal manufacturing is impacting on urban contexts through the emergence of new types of mini factories (Lipson \& Kurman 2010), while jobs are being rapidly transformed due to the increased need for flexibility and mobility in a blurred market. Many platforms/services (Quirky.com, garagedesign.it, etc.) have emerged that support co-working and urban making, where design has moved to the forefront of the industrial/business process from idea generation to technical development and distribution/sale.

Two solutions developed by students addressed this topic:

- 3Dealize: this proposed an urban laboratory that empowers the creative capital of Milan through 3D printing. It envisions new technologies as the means to reconnect cities and manufacturing, and has designed the stimulation of creative encounters between designers and citizens through making workshops and an equipped urban laboratory to promote learning 
through practice. As with the apprentice, the service enables learning through the practical exchange of experience. It also proposed a catalogue to collect the ideas of all participants to the community - the 3Dealize community.

- Studio on Demand: a service for collaborative curriculum building within universities. It is based on the connection between urban facilities, academia, and local businesses. Studio on Demand involves students and firms collaborating on specific design issues, allowing a mix of skills and people. A new way to enter the job market is experienced by students within the university, where loyalty to a single organisation is overcome by flexibility, adaptability and experience.

\section{City and neighbourhoods}

This topic addressed the possibility of enabling local networks to create better solutions for their daily problems. Different organisation models based on sharing, exchanging and participating within neighbourhoods are emerging to regenerate the social fabric, and create meaningful interactions between social actors, such as purchasing groups, networks to barter/swap/trade/lend objects and skills. These all aim at creating a longer cycle in the life of goods while improving the quality of human life (Mulgan 2007; Murray et al. 2010). For example, local resources are key elements for reviving urban assets, and food systems represent one of the most important medium to give new value to territories (for example, the Slow Food Movement, the idea of short chains, the ZeroMiles label).

Two service design propositions addressed this topic:

- Tatà: a neighbourhood-based and family-based service that connects citizens to support each other in daily needs. A community of families helps each other and networks to improve day care services for children. The final goal is to amplify participation and trust starting from a single building, and enlarging it to a neighbourhood, and a community. Families are asked to subscribe for mutual exchange of time, sharing needs, behaviours and activities. The Tatà community is thus able to support users in scaling, arranging, and customising the solution to respond to their own needs, collaborating and participating for short or long periods of time.

- Yummi: a network of local producers (cascine) and travellers interested in understanding the local culture for producing, transforming and preparing food. It creates a one-to-one relationship: with no intermediaries, urban farmers propose guests to witness in flesh a day in a Milanese farm. Yummi gives new value to local resources by transforming them into hubs for knowledge sharing and craft learning. This process is based on teaching and sharing local food tradition from farm workers to travellers. The networks and the connections between local producers and travellers changes constantly and the service experience is reinforced by the creation of strong interdependence between farmhouses, local producers and service providers. 


\section{City and local craft}

This topic is related to connecting local experts in traditional knowledge (the craftspeople) to design networks for generating new ways to experience tradition. Craft is one of the most important resources for the Italian economy, as it characterises a good portion of the national socio-productive culture. The ability to make something with one's hands remains a distinctive trait of the Italian socio-economic system, which is looking for new development in the face of the current economic crisis. On the other hand, Italy has an important cultural industry linked to tourism, museums, cultural heritage, traditions and history, which can be considered one of the privileged assets to strengthen city resources (Landry 2006), by adding value to both new and traditional goods and services.

Two services have addressed this:

- Rinnovami connects artisans, designers and citizens to give new value to the craft knowledge diffused in a big city like Milan. It offers furniture renovation where designers are the facilitators of the process, while the network of artisans guarantees the high quality of the results. This service underlines the idea that building effective connections is fundamental to enable mutual help in neighborhoods - here, through an intervention on surfaces and small components such as furniture - and how this also increases the visibility and accessibility of urban networks.

- Italian Job proposes a new way to access the city through experiencing traditional craft shops, quality and tradition, and through providing customised travel packages for an exclusive journey into traditional tailors, leather artisans and barbers. Starting from the perspective that local knowledge is a key resource of the urban capital and a lever for innovation, the service creates new business and job opportunities for strengthening the local craft community based in Milan. It defines a 'tailored' way to experiencing traditional knowledge through craft practices. The community of artisans and users strengthens the local tacit networks and reinforces links with a wider group of people and competencies.

\section{The description of crafted social innovations: the temporary community of makers}

Analysing the above solutions, some common elements emerge that characterise a design solution for social innovation. These include a focus on the collective dimension, on human interactions and co-creation; on mutual learning processes characterised by exchange of ideas and knowledge; on the design of trust, reciprocity, negotiation, and conversation, and on the link with the resources of a place to devise complex systems based on collaborative platforms online and offline. 
All projects address specific challenges proposed by social innovation, namely they aim at empowering people in designerly ways, thus enabling citizens to improve their current practices. People and their needs are at the centre of all solutions, thus applying a systemic approach to innovation, where collaboration, participation and networking are designed for. In particular, each solution stresses the centrality of a collective subject to trigger and to own the action and the process of change. This is especially interesting, because it represents the central focus for enabling/crafting social innovations. We have called this collective subject the temporary community of makers (Mortati \& Villari 2013), basing it on three characteristics:

- Temporary as the group that promotes the solution is formed around a common project and shares some interests. These remain in common following the evolution of the initiative. Once goals are achieved, the community is transformed into something new - participants become the enzymes for future actions.

- Community as it contains all of the characteristics of a community of practice (the members are interdependent and support each other in a mutual learning process - Wenger 1998). The collective subject is also the main actor in the process, and is different from the sum of its parts (citizens, local institutions, professionals, amateurs, and so on).

- Makers as the community originates to make something that is designing and developing an idea in particular contexts, sharing languages and tools.

The idea of a temporary community of makers emphasises also the extreme complexity of a solution in which social and economical needs must all be satisfied, and where different strategic aims need to be combined. We argue that these kinds of communities are the central focus for designers wanting to impact on social innovation: they represent the people to design for and design with.

The temporary community of makers is based on sharing practices and on the mutual engagement of people, who help each other in improving skills. In the process of designing such community, the objects 'crafted' have a different nature; i.e., through doing/making. They can be services, enterprises and policies. The members of this community can perform varying roles, such as designer, practitioner, citizen and policy maker; activities are bottom up and self-organised. Moreover, solutions are applied at small scale and are not always able to be replicated in other contexts; they are complex interventions specific to a place, and emerge from collective processes.

\section{Discussion}

In this paper we have reflected on how design can be a driver for social innovation in urban contexts by describing a two-year research path from a theoretical perspective to an on-field experimentation developed during a six months masters studio. 
Reflecting on the set of skills identified during the first phase of the project (skills to provoke collaboration, to foster participation, and to enable networks), we have built a teaching framework to educate social innovators. This was based on the principles of learning by doing, and thinking by prototyping, and has accompanied students in iterative cycles of qualitative research that are particularly focused on prototyping.

We have argued that design is relevant to promoting social innovation as both enabler and participant to the collective subjects that can foster transformation. We have called this a temporary community of makers, as it is born around a common objective, to make something, and evolves following the life cycle of the initiative. These collective subjects can be designed for through the filters of collaboration, participation, and networking.

The discussion developed throughout the article opens new and relevant research areas for design that we are exploring further on two levels: with design students, by looking into a twofold application concerning products and services; and, with local administrations and communities to explore specific design tools for social innovation. The expected outcomes will aim to reinforce the understanding of the framework proposed and the role of temporary communities of makers in creative strategies for enhancing places.

Finally, the paper identifies a contemporary connection between design and craft, not only in the approach for producing a final good (designed object), but also through extracting and applying skills and attitude for educating future designers. We thus propose to researchers within educational contexts, such as masters studios, to further reflect on the idea of educating and learning as crafting, as an effective approach to renovate design education, and to further nuance the connection and potential between design and social innovation.

Marzia Mortati is Researcher and Lecturer in Design at Politecnico di Milano. Her research interests concern the topic of Collaborative Networks, Design and Innovation, SMEs and connectivity. Currently she is involved in international researches concerning design and innovation, design policies, and social innovation. Since 2007 she has worked in the faculty of the Master Degree in Product/Service Systems Design at Politecnico di Milano.

Beatrice Villari is Researcher at Politecnico di Milano and works on service design, strategic design and design for local development. Currently she is involved in international research activities and projects on design and social innovation and design policies. She is based in the faculty for the Masters Degree in Product/Service System at Politecnico di Milano, where she coordinates one of the Final Studios on service design. 
craft + design enquiry

\section{References}

Associate Parliamentary Design \& Innovation Group (APDIG), 2013, Restarting Britain 2. Design and public services, viewed 8 April 2013, http://www. policyconnect.org.uk/apdig/redesigning-public-services-inquiry-report

Bureau of European Policy Advisors (BEPA), 2011. Empowering People, Driving Change: Social innovation in the European Union, Luxembourg: Publications Office of the European Union, viewed 20 Oct. 2012, http://ec.europa.eu/ bepa/pdf/publications_pdf/social_innovation.pdf

Bettencourt, L.A. \& West, G.B. 2011, 'Bigger cities do more with less', Scientific American, vol. 305, no. 3, pp. 52-53.

Bonomi, A. \& Bruzzese A. 2004, La Città Infinita, Milano: Bruno Mondadori.

Botsman, R. \& Rogers, R. 2010, What's Mine Is Yours, New York: HarperBusiness.

Bovaird, T. 2007, 'Beyond engagement and participation: User and community coproduction of public services', Public Administration Review, vol. 67, no. 5 , p. 846.

Bradwell, P. \& Marr, S. 2008, 'Making the most of collaboration: An international survey of public service co-design', Demos Report 23, viewed 6 Oct. 2012, http://www.demos.co.uk/publications/makingthemostofcollaboration

Bunt, L. \& Harris, M. 2010, Mass Localism: A way to help small communities solve big social challenges, London: NESTA, http://www.nesta.org.uk/library/ documents/MassLocalism_Feb2010.pdf

Burns, C., Cottam, H., Vanstone, C., \& Winhall, J. 2006, Red Paper 02: Transformation Design, London: Design Council, http://www.designcouncil. info/mt/RED/transformationdesign/TransformationDesignFinalDraft.pdf

Cottam, H. \& Leadbeater, C. 2004, Red Paper 01: Health: Co-creating services, London: Design Council, http://www.designcouncil.info/RED/health/ REDPaper01.pdf

Ellis, T. 2010, The New Pioneers: Sustainable business success through social innovation and social entrepreneurship, Chichester: John Wiley \& Sons, Ltd.

European Union (EU), 2009, 'Design as a driver of user-centred innovation', working paper, Brussels: Commission of the European Community, viewed 6 Aug. 2012, http://ec.europa.eu/enterprise/policies/innovation/policy/ design-creativity/index_en.htm

Florida, R. 2002, The Rise of the Creative Class and How it's Transforming Work, Leisure, Community and Everyday Life. New York: Perseus Book Group. 
Frayling, C. 2011, On Craftsmanship Towards a New Bauhaus, London: Oberon Books.

Holmlid, S. 2009, 'Participative, co-operative, emancipatory: From participatory design to service design', First Nordic Conference on Service Design and Service Innovation, Oslo, Norway.

Kahn, L., Ali, A., Buonfino, A., Leadbeater, C. \& Mulgan, G. 2009, Breakthrough Cities: How cities can mobilise creativity and knowledge to tackle compelling social challenges, The Young Foundation, British Council.

Landry, C. 2000, The Creative City: A toolkit for urban innovators, London: Earthscan.

- - 2006, The Art of City Making, London: Earthscan.

Lipson, H. \& Kurman, M. 2010, 'Factory @ home: The emerging economy of personal manufacturing', Occasional Papers in Science and Technology Policy, Science and Technology Policy Institute, viewed 15 Oct. 2012, web. mae.cornell.edu/lipson/FactoryAtHome.pdf

Lukensmeyer, C.J., Hasselblad L.T. 2006, Public Deliberation: A manager's guide to citizen engagement, IBM Center for the Business of Government.

Manzini, E. 2011, 'Social innovation and design: How designers can trigger and support sustainable changes', Cumulus Conference: Shanghai Young Creators for Better City \& Better Life. Shanghai, 6-10 Sept. 2010.

Meroni, A. \& Sangiorgi D. 2011, 'A new discipline', in A. Meroni \& D. Sangiorgi (eds), Design for Services, Aldershot, UK: Gower Publishing, pp. 9-33.

Mortati, M. \& Villari, B. 2013, 'Connected communities of makers', Crafting the Future, Gothenburg 16-19 April 2013.

Mulgan, G. 2007, 'Social innovation: What it is, why it matters, and how it can be accelerated', working paper, Skoll Center for Social Entrepreneurship, viewed 6 Oct. 2012, http://www.sbs.ox.ac.uk/centres/skoll/research/ documents/social innovation.pdf

Murray, R., Caulier-Grice, J. \& Mulgan G. 2010, The Open Book of Social Innovation, The Young Foundation and NESTA, viewed 12 Oct. 2012, http:// www.nesta.org.uk/publications/assets/features/the_open_book_of_social_ innovation

Nussbaum,B.2011, 'DesignersarethenewdriversofAmericanentrepreneurialism', viewed 12 June 2012, http://www.fastcodesign.com/1665120/designersare-the-new-drivers-of-american-entrepreneurialism

Owen, C. 2007, 'Design thinking: notes on its nature and use', Design Research Quarterly, vol. 1, no. 2, pp. 16-27. 
Sanders, E.B.N., 2006. 'Scaffolds for building everyday creativity', in J. Frascara (ed.), Designing Effective Communications: Creating Contexts for Clarity and Meaning, New York: Allworth Press.

Sanders, E.B.N. \& Stappers, P.J., 2008, 'Co-creation and the new landscapes of design', Codesign, vol. 10, no. 2, pp. 63-77.

Sangiorgi, D., 2011, 'Transformative services and transformation design', International Journal of Design, vol. 5, no. 2, pp. 29-40.

Sennet, R. 2008, The Craftsman, USA: Penguin Books.

Simon, H.A. 1969, The Sciences of the Artificial, Cambridge, MA: MIT Press.

Schön, D. 1983, The Reflective Practitioner, London: Temple Smith.

Thackara, J. 2005, In the Bubble: Designing in a complex world, Cambridge: MIT Press.

Villari, B. 2012, Design per il territorio. Un approccio community centred, Milano: FrancoAngeli.

Wenger, E. 1998, Communities of Practice: Learning, Meaning, and Identity,Cambridge University Press.

Wenger, E., McDermott, R. \& Snyder, W.M. 2002, Cultivating Communities of Practice, Harvard Business Press.

Young Foundation, 2008. The Collaborative City: Working together to shape London's future, Mar., viewed 10 Oct. 2012, http://www.youngfoundation.org 